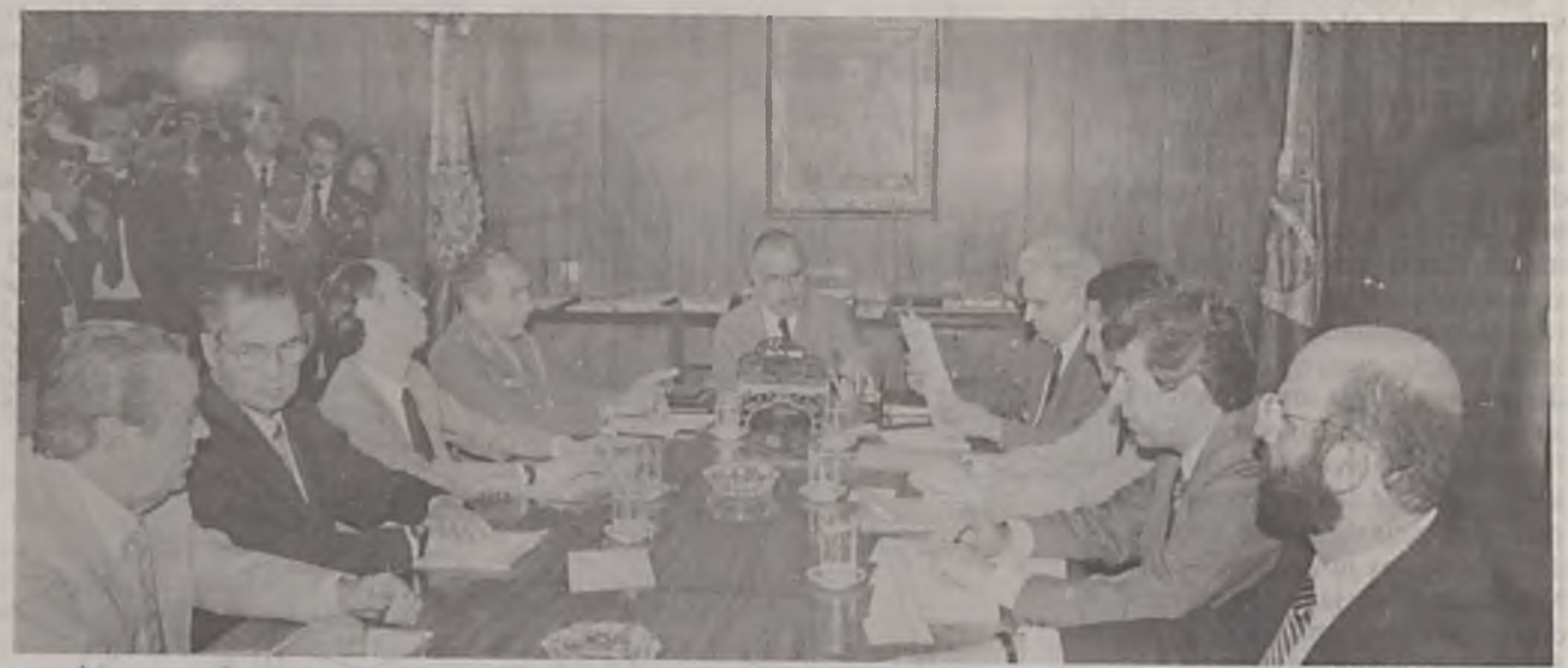

() presidentc José Sarney assinou os decretos, presentes apenas os ministros envolvidos e os ministros "da Casa"

\title{
Reforma é o resultado de longa jornada de trabalho
}

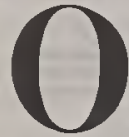
objetivo da reforma administrativa é mudar a cultura da organização pública brasileira, longamente exposta a um processo de caducidade. Enxugar o déficit público, extinguir, fundir ou incorporar órgãos públicos tudo isso será decorrência, a prazos mais amplos, do processo de reforma iniciado. E um processo sem prazos fatais para dar resultados concretos, pois a mais lenta e gradual das reformas é a que mexe com a cabeça e com as mentalidades.

Por isso estamos apenas no inicio. A primcira clapa da reforma foi iniciada em 31 de julho de 85, no Palácio do Planalto, quando o presidente Sarney instalou oficialmente a Reforma Administrativa, dando posse a 36 membros de sua Comissão-Cieral, recrutados de todos os segmentos da sociedade pensante brasileira, de organizações universitárias e instituiçőes de pesquisas. Muitas dessas personalidades Irouxeram para a comissãogeral a experiência de uma participaçāo anterior em reformas administrativas.

Empossados os integrantes, a comissão-geral foi subdividida em câmaras c comissões especiais, que envolveram, ao todo, cerca de 420 lécuicos, recrutados para darem pareceres c consultas sobre os diversos âmbitos cufocados. De agosto de 85 a feverciro de 86 , a comissão-geral teve o papel fundamental de avaliar c diagnosticar os pontos de emperramento da administração pública brisilcira, produzindo documentos de diretrizes - sobre politica de pessoal, sobretudo - que iriam dar elementos para a fase posterior do esforco da reforma.

Plano cruzado trouxe desafio novo - com a edição do Plano de Estabilizaçao Econômica, em fevereiro, houve uma mudança drástica das intençòes do governo em face de mudanças substanciais no comportamento do poder público. Era a maior lentativa de mudança de mentalidade já posta em prática pelo Poder Executivo, reorientando a sociedade a aderir a um projeto de existência condigna, distante da inflação, da especulação financeira e da supervalorização dos ganhos sem trabalho e produção real. O Plano Cruzado exigiu imediatamente a adequação do setor público ao processo de mudanças a que o setor privado rapidamente se adaptou. Era preciso dar mais velocidade à Reforma Administrativa, para que acompanhasse o processo deflagrado pelo Plano Cruzado.

Em abril, a Reforma Administrativa passou a ter um procedimento de debates interministeriais, comprovando o trabalho em equipe e a necessidade de discussōes democráticas e transparentes, a nivel técnico, das propostas até então sugeridas pela Comissão-Geral. A necessidade de transparência e amplitude nas trocas de opinião entre os diversos setores do governo federal interessados foi uma constante, comprovando o espirito de reforma conceitual, que mexe com a cultura das organizaçōes - a mais resistente a mudancas.

Mas valeu a pena o exercicio de debates interministeriais, entre representantes dos Ministérios da Administração, Fazenda, Seplan e Gabinete Civil da Presidência. A proposta tomou forma, em abril, com a discussão intramuros sobre o tipo de Reforma $A d m i n i s t r a t i v a$ que o governo queria. Mais tarde foi agregado o Ministério do Trabalho às trocas internas de opinião, que passaram ao nivel dos ministros diretamente envolvidos. Era a fase de de- 
cidir qual era a etapa prioritária da reforma.

A imprensa noticiou, nessa fase, muitas divergências de opiniāo, mas que jamais vieram a obstacular o entendimento. Esses desencontros de criterios serviram, geralmente, como incentivo à busca de maiores aprofundamentos para o alcance de uma unidade de pensamento entre os setores governamentais encarregados da reforma. Finalmente, saiu o grupo definitivo que iria mais tarde compor o Gerap (Grupo Executivo da Reforma da Administração Pública).

Objetivos primordiais do governo - O presidente Sarney colocou permanentemente, ao longo de seu governo, a idéia da reforma da máquina, no sentido de agilizála, tornando-a competente e modernizada. Sempre preocupou ao Presidente a impermeabilidade da circulação das decisōes do poder civil, a Ientidão com que essas ordens são processadas, e a burocratizaçāo do andamento de medidas já decididas pelo governo.

O ministro Aluízio Alves, em seus despachos com o Presidente da República, sempre trouxe dele incentivos crescentes para prosseguir em seu trabalho de mudanças na administração, removendo velhos costumes e mordomias enraizadas, mesmo que essas alteraçoes produzissem focos de pressão terriveis sobre o governo. A ordem era democratizar e mudar o serviço público.

$\mathrm{O}$ que o Governo Federal de fato procura com a Reforma AdminisIrativa? Pode-se resumir em três os objetivos:

1) a modernidade do serviço público, em termos de sua compatibilidade com os modernos processos de gestão já presentes na iniciativa privada;

2) a adequação do serviço público a padrōes de eficiência para poder viabilizar programas e projetos do Governo, como o Plano Cruzado e o Plano de Metas;

3) maior eficácia na prestação de serviços públicos ao cidadão.

Tudo o mais - como a extinção, fusão ou incorporação de órgãos federais,enxugamento de déficit público, remocão de funcionários - é subproduto desses objetivos principais. $\mathrm{O}$ que se quer é a adequação da máquina da administração direta aos nadrỏes de gestão e agilidade decisória já alcançados pela adminis-

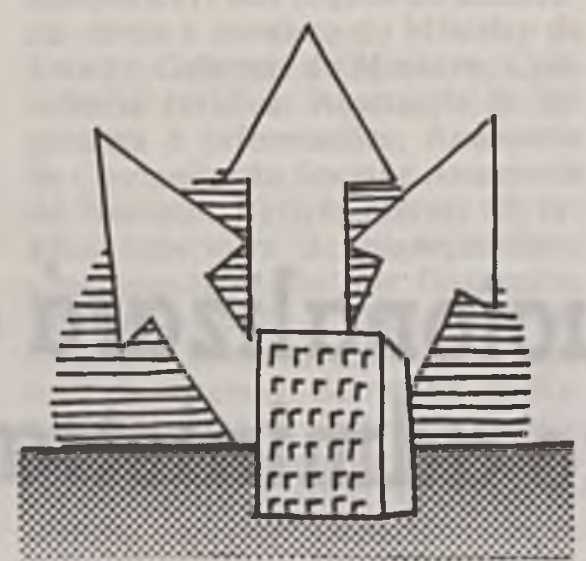

iração indireta. Não era compativel ao governo federal ter um lado de sua administração burocratizado, inerte e desmotivado, assistindo ao outro lado, dentro desse mesmo governo, buscar e implementar formas gerenciais de se tornar eficiente e competitivo.

Fortalecimento da administração direta - A procura de uma administração pública condizente com aqueles três objetivos (modernidade, adequação aos programas do governo e eficiência) foi demonstrada, em sua urgência e necessidade, pelos diagnósticos produzidos durante os meses de estudos que anteçederam à assinatura dos oito primeiros decretos da Reforma Administrativa, pelo presidente José Sarney, no Palácio do Planalto, a 3 de setembro último.

O diagnóstico mostrou que, enquanto a administração indireta havia criado procedimentos mais ágeis de decisão e gestão, a direta se burocratizava cada vez mais, tornandose inadequada para o cumprimento de sua função maior de coordenação, controle e execução das tarefas de Estado. Era como se o Governo Federal tivesse sua cabeça enfraquecida enquanto seus membros se fortaleciam, tornando-se uma massa letárgica, sem estimulo para sua grande base funcional, e mantendo processos irregulares de acesso a seus quadros.

Somente após essa reversão de expectativas, revalorizando-se a administração direta, é que se poderá fazer o enxugamento da máquina administratriva federal. Primeiro, há que se motivar o funcionalismo públicu, azeital os procedimentos para que obtenha agilidade, e racionalizar todos os seı viços públicos que hoje tornam o Estado, por herança do passado, uma grande panacéia de concessōes paternalísticas e usos indevidos de seus recursos.

O enxugamento da máquina virá a médio prazo, até como decorrência de maior preparo da estrutura legal, permitido pelos primeiros decretos assinados pelo presidente Sarney com os cinco ministros que integram o grupo da Reforma AdminisIrativa.

Esse enxugamento dará uma perspectiva de mudança drástica ao serviço público, pois hoje os contribuintes da União são obrigados a sustentar uma máquina defasada e superposta em muitas de suas áreas, como a do abastecimento - verdadeiro desafio do Governo Federal para viabilizar o Plano Cruzado mas que está polvilhada pela presença de nada menos de 48 órgãos, que atuam sob um paralelismo total.

Pessoal e licitações: mudanças urgentes - Nas discussðes finais dos grupos interministeriais do governo, finalmente, chegou-se a pontos de vista consensuais quanto à premência de se dar prioridade à mudança das políticas de pessoal e de licitações do serviço público. São dois aspectos que tornam evidentes os processos de inadequação do setor público: primeiro, a falta de uma politica de pessoal que valorize o funcionalismo pelo mérito e pelo acesso a uma carreira vertical. $O$ último Estatuto do Servidor Público, datado de 1952, já não atendia às novas exigências do corpo funcional da administração pública dentro dos ordenamentos modernos que regem as relaçōes de trabalho numa sociedade socialmente competitiva. Há que se dar ao servidor público a certeza de uma carreira digna e respeitável, comr treinamento e aperfeicoamento para a promoça aos diversos niveis de sua ascensão funcional, para a auferição de uma remuneração compativel com a responsabilidade de cada função.

Outro aspecto que obteve consenso, em torno de mudanças prioritárias, foi a politica de licitaçoes, praticada desde o Decreto-lei 200, e que passou três anos para ser elaborada, tal a sua complexidade. No entanto, os tempos atuais exigem uma legislaçao menos complexa e 'mais dinâmica, salvaguardadora dos interesses patrimoniais da Uniāo, mas sem criar empecilhos para a racionalização das açōes administrativas do Governo Federal. 